\title{
FRAUDE CONSTITUCIONAL À VISTA: SERIA A CONSTITUIÇÃO DE 1988 PASSÍVEL DE NOVA REVISÃO?
}

\section{CONSTITUTIONAL FRAUD IN SIGHT: WOULD THE 1988 CONSTITUTION BE SUBJECT TO ANOTHER REVISION?}

\author{
Ivo Dantas ${ }^{1}$ \\ Emiliane Alencastro ${ }^{2}$ \\ Ivo Dantas Filho ${ }^{3}$
}

\section{RESUMO}

Este trabalho enfrenta se é possível que seja realizada uma nova Revisão na Constituição brasileira de 1988. A Revisão constitucional, enquanto espécie de ato do Poder de Reforma, tem seus contornos definidos pelo Poder Constituinte, sendo premente compreender adequadamente o que foi estabelecido na Constituição. A importância desta pesquisa está no fato de que seu resultado tem grande relevância para a manutenção da higidez constitucional e, por conseguinte, do ordenamento jurídico. Para tanto, foi realizada uma pesquisa bibliográfica e documental, a partir do método hipotético-dedutivo. Conclui que não é possível que seja realizada nova Revisão constitucional, de modo que deve ser dada uma interpretação restritiva às disposições que estabelecem espécies de atos de Reforma.

Palavras-chave: constituição de 1988; poder constituinte; revisão constitucional; teoria da constituição; poder de reforma.

\section{ABSTRACT}

This research answers whether it is possible to carry out a new revision of the 1988 Brazilian Constitution. The constitutional revision, as a kind of act of the Reform Power, has its contours defined by the Constituent Power, and it is urgent to properly understand what was established in the Constitution. The importance of this research lies in the fact that its result has great relevance for the maintenance of the constitutional system and, consequently, of the legal system. Therefore, a bibliographical and documentary research was carried out, using the hypothetical-deductive method. It concludes that it is not possible to carry out a new constitutional revision, so that a restrictive interpretation must be given to the provisions that establish types of Reform acts.

\footnotetext{
${ }^{1}$ Professor Titular da Faculdade de Direito do Recife - UFPE. • Doutor em Direito Constitucional - UFMG. Livre Docente em Direito Constitucional - UERJ. • Livre Docente em Teoria do Estado - UFPE. • Membro da Academia Brasileira de Letras Jurídicas. • Membro da Academia Brasileira de Ciências Morais e Políticas. • Presidente do Instituto Pernambucano de Direito Comparado. • Presidente da Academia Pernambucana de Ciências Morais e Políticas. • Miembro del Instituto IberoAmericano de Derecho Constitucional México). • Miembro del Consejo Asesor del Anuario IberoAmericano de Justicia Constitucional, Centro de Estudios Políticos y Constitucionales (CEPC), Madrid. • Ex- Diretor da Faculdade de Direito do Recife - UFPE. • Membro da Academia Pernambucana de Letras Jurídicas. • Fundador da Associação Brasileira dos Constitucionalistas Democráticos. • Membro Efetivo do Instituto dos Advogados de Pernambuco. • Membro do Instituto Pimenta Bueno - Associação Brasileira dos Constitucionalistas. • Professor Orientador Visitante do Programa de Pós-Graduação em Ciências da Saúde, Universidade Federal do Rio Grande do Norte, conforme aprovação do Colegiado, em 31 de maio de 2001.• Juiz Federal do Trabalho - (aposentado). • Advogado e Parecerista.

${ }^{2}$ Mestranda em Direito pelo PPGD, Faculdade de Direito do Recife. ${ }^{2}$ Especialista em Direito e Processo do Trabalho, pela UNICAP.

${ }^{3}$ Especialista em Direito e Processo do Trabalho, pela UNICAP.
} 
Keywords: 1988 constitution; constituent power; constitutional review; constitution theory; Reform power.

\section{INTRODUÇÃO}

Em tempos de crise institucional como o atual - para não falar das outras que afligem o Constitucional brasileiro -, a análise de temas correlatos à alteração da Constituição se faz de extrema necessidade. Especialmente quando se trata de uma Constituição como a brasileira, cujo Poder de Reforma, nesses mais de trinta anos (1988-...), foi usado e abusado, inclusive perpetrando inconstitucionalidades flagrantes. De maneira ainda mais grave, o Poder de Reforma se encontra ameaçado sempre que se fala em Assembleia Constituinte ou na realização de uma nova Revisão, ${ }^{4}$ sendo esta última objeto deste trabalho.

O estudo proposto nos põe diante de ato que atordoa todo escritor (e também o escritor da Constituição): a revisão de um texto. É revendo seu escrito que um literata aprimora seu texto, corrigindo-o, adaptando-o. Nesse caminho, o escritor não deve se dispersar da identidade do original, sob pena de a "re-visão" se convolar em "visão", produzindo um inteiro novo texto, criando uma crise identitária, perdendo-o em "não sei quantas almas". 5

Um ponto inicial deve ser trazido à colação. Apesar de se tratar de fenômeno jurídico, o estudo do Poder de Reforma (gênero cujo uma das espécies é a Revisão) se conecta com fenômenos políticos, o que não deve atemorizar a análise do tema, sobretudo, para não deixar que as convicções ideológicas inconscientes de cidadão comprometam a análise científica. ${ }^{6}$ A existência dessa conexão, em verdade, não impede que o Poder de Reforma seja analisado enquanto fenômeno jurídico, conjuntura em que o objeto de pesquisa é avaliado com métodos próprios da ciência jurídica.

Feito esse destaque, é importante sedimentar que o estudo acerca da possibilidade de nova Revisão, sob o método da interpretação constitucional sistêmica, considerou a Constituição brasileira de 1988. Afinal, o enfrentamento da pergunta que dá título a este estudo pretende chegar a uma resposta embasada no atual constitucionalismo brasileiro, de modo que esta exposição está voltada para o nosso momento histórico-jurídico. Para encontrar resposta para o quesito feito, como caminho, foi necessário examinar a diferença entre Emenda e Revisão, uma vez estabelecida a premissa de que se trata de espécies de ato do Poder de Reforma, bem como questionar qual o método de interpretação deve ser aplicado ao art. $3^{\circ}$ do ADCT, que prevê a possibilidade de Revisão constitucional, o que terá o poder de definir se é possível realizá-la novamente.

No enfrentamento dessas questões, foi percorrido um sinuoso caminho. Inicialmente, foi estabelecido o conceito científico dos institutos "Poder Constituinte" e "Poder de Reforma", a fim de melhor sedimentar os contornos da Revisão, enquanto espécie de ato do Poder de Reforma. Em seguida, foi feita uma análise do tema no direito estrangeiro, especificamente nas Constituições Italiana, Espanhola e Portuguesa, por terem servido de inspiração para o modelo brasileiro. Por fim, foi realizado um estudo das disposições textuais da Constituição brasileira de 1988, a fim de estabelecer as diferenças entre revisar e emendar, bem como a extensão do art. $3^{\circ}$ do ADCT, a partir das regras procedimentais, já que os limites materiais são os mesmos.

O resultado da pesquisa tem grande relevância para a manutenção da higidez constitucional

${ }^{4}$ Cf. DANTAS, Ivo. Poder Constituinte e Revolução. Breve introdução à Teoria Sociológica do Direito Constitucional. 2. ed. Bauru: Jalovi, 1985; Teoria do Estado Contemporâneo. 3. ed. Curitiba: Juruá Editora, 2016.

5 O excerto entre aspas faz referência ao poema (de domínio público) de Fernando Pessoa, "Não sei quantas almas tenho", literata de referência, que no poema referendado traz como tema central a complexa identidade edificada às turras com algumas dúvidas existenciais, gerando um eu múltiplo.

6 Cf. DANTAS, Ivo. Instituições de Direito Constitucional Brasileiro. 3. ed. Curitiba: Juruá Editora, 2014. 


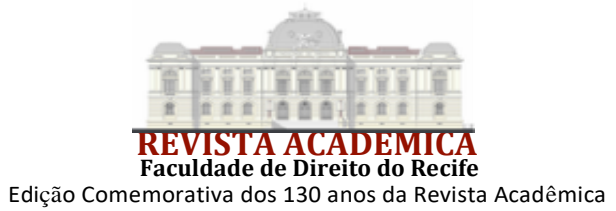

e, por conseguinte, do ordenamento jurídico. Por exigir uma análise das teorias construídas, especialmente porque os elementos do objeto a ser pesquisado são eminentemente teóricos, a metodologia utilizada foi a pesquisa bibliográfica e documental, haurindo recursos doutrinários que possibilitem analisar o objeto proposto. Para a construção da análise, foi adotado o método hipotético-dedutivo, formulando-se conjecturas possíveis a partir da bibliografia e documentação avaliadas, de modo que a conclusão da pesquisa encontra, necessariamente, seu suporte teórico nas premissas dispostas pela técnica de pesquisa adotada.

\section{O PODER CONSTITUINTE E O PODER DE REFORMA: EMENDA E REVISÃO CONSTITUCIONAIS COMO FORMAS DE MANIFESTAÇÃO DO PODER DE REFORMA}

Ao lado das garantias individuais e coletivas, atualmente objeto de estudos do Direito Processual Constitucional, as Constituições contemporâneas também estabelecem suas próprias garantias, exercidas pelo controle de constitucionalidade que visam a permanência sob o ângulo sociológico da supremacia constitucional que, do ponto de vista jurídico, transforma-se em supralegalidade e em imutabilidade relativa.

Esse imponente sistema de garantias próprias só é possível em razão da natureza do poder que elabora a Constituição: o Poder Constituinte. ${ }^{7}$ Com base na lição de Georges Burdeau, em "Traité de Science Politique", ${ }^{8}$ trata-se de poder que é inicial, autônomo e incondicional, razão pela qual não sofre limitações do ordenamento que precedeu a sua instalação através da Assembleia Constituinte.

Nesse momento, ele (Poder Constituinte) institui o Poder de Reforma constitucional, órgão derivado, limitado e condicional, que é entregue a determinadas instituições expressamente previstas no texto constitucional vigente, incumbindo-o de estabelecer as mudanças (quando necessárias) para adaptar à realidade social o texto jurídico-positivo. Nesse quadrante, também antevê o procedimento que deverá ser seguido. O Poder Constituinte, que se apresenta como um Poder de Fato, cria um Poder Jure, que é o Poder de Reforma. ${ }^{9-10}$

Nesta altura do raciocínio, é necessário que detalhemos o que poderíamos chamar de Revolução, sob o ângulo da Sociologia do Direito Constitucional enquanto sistema, fenômeno decorrente da não aceitação espontânea do Direito Vivo pelo poder político. A Revolução

7 O fundamento da supremacia constitucional varia na doutrina. Alguns autores dispõem que decorre da natureza do poder que elabora a Constituição, o poder constituinte. Nesse sentido: SIEYÈS, Emmanuel Joseph. Observaciones sobre el informe del comité de constitución acerca de la nueva organización de Francia. Introdução, estudo premiliminar e compliação: David Pantoja Morán. Fondo de Cultura Económica: México, 1993.

8 BURDEAU, Georges. Traité de Science Politique. 10. ed. Paris: Librairie Générale de Droit et de Jurisprudence, 1969. p. 184-185. t. 4. Do mesmo autor, Droit Constitutionnel et Institutions Politiques. 6. ed. Paris: LGDJ, 1974. p. 55 et seq.

9 "Urge que chamemos a atenção para um detalhe de fundamental importância: o Poder Constituinte é essencialmente político (ou sociológico) por não ser instituído. Os demais - inclusive o de Reforma -, impropriamente chamado de constituinte derivado - são instituídos e, portanto, poderes jurídicos, cujo exercício e desempenho se encontram limitados pelas normas jurídicos-constitucionais vigentes. O primeiro é Poder de Fato, enquanto os demais são Poderes de Jure. O primeiro contraria as normas vigentes; o segundo lhes é fiel, inclusive, para garantir a permanência constitucional, por necessidades de técnica legislativa constitucional..."

DANTAS, Ivo. Poder Constituinte e Revolução: breve Introdução à Teoria Sociológica do Direito Constitucional. 2. ed. Bauru: Jalovi, 1985. p. 25.

10 É importante mencionar a impropriedade de termos comumente utilizados na doutrina para se referir ao Poder de Reforma, tais como poder constituinte derivado ou de segundo grau. O poder ou é originário ou é derivado e nesta última situação não cabem denominações como "poder constituinte derivado" ou de "poder constituinte de segundo grau", havendo até quem use "poder constituinte constituído" e tantas outras que pecam em sua formação pela incompatibilidade dos dois termos forçadamente usados para criar uma nova expressão, cientificamente inaceitável. 
consubstancia uma espécie de Poder de Reforma não institucionalizado, tratando-se de um passo brusco rumo à mudança, em sobreposição da realidade sobre o Direito. É dado integrante da fenomenologia política, que trará reflexos para o ordenamento jurídico.

Passa a ser oportuna, portanto, a definição de Direito Vivo, expressão criada por E. Ehrlich, compreendendo a lei viva em contraste com aquela que está sendo aplicada nos tribunais. A lei viva é aquela que domina a vida, embora não tenha sido posta em proposições jurídicas. ${ }^{11}$

Apesar da amplitude do conceito defendido pelo festejado pensador austríaco, não desconhecemos nem negamos dois dados: (i) o Direito Vivo se interpenetra no Direito Oficial, não sendo muito provável que se consiga fixar uma linha demarcadora entre ambos; (ii) além daqueles valores comuns a todas as camadas que formam uma determinada sociedade, existem outros que são "privativos" de cada estrato social.

Ocorrendo a Revolução, em nome de valores sociais e do Direito não legislado, evidentemente todo o sistema jurídico-constitucional será posto de lado e uma nova estrutura jurídica deverá brotar com base nos ideais revolucionários. A Revolução tem o poder de revogar e destruir o Direito legislado, a partir da ação explosiva de forças oprimidas que ela desencadeia e a substitui por outra, considerando as novas demandas sociais. "O objetivo principal de qualquer Revolução é a supressão da ordem jurídica pré-existente e sua substituição por uma nova". ${ }^{12-13}$

Diante da Revolução, desenvolve-se, por assim dizer, quase um processo dialético, em que a realidade se apresenta como antítese. A formulação de uma nova ordem correrá os mesmos riscos da anterior, caso não haja adaptação do Direito legislado à realidade social existente.

Chamemos a atenção para um detalhe: vitoriosa a Revolução, seus líderes, ao assumirem o poder, começam os procedimentos necessários para atingir a ordem jurídica nos pontos em que era inconstitucional, devido a omissões ou ações. Contra ela será deflagrado, após o afastamento destas inconstitucionalidades, o processo de juridicização positiva da sociedade. Este processo tem início por intermédio do Direito Transitório, através do qual não se tem de logo as linhas definitivas da nova organização, mas sim a fixação dos objetivos primordiais do movimento, que, se em princípio era algo anti-lei, anti-jurídico, em um segundo momento será fonte do Direito Positivo, através da qual será elaborada a viga mestra do novo sistema: a Constituição Política (jurídica).

Estudando o primeiro período desta nova elaboração do sistema jurídico, Clóvis Ramalhete entende que nele existem funções, resumindo-as em duas: (i) inicia o processo de ruptura da ordem jurídica estabelecida; (ii) prepara o advento das transformações do Direito pela insurreição. ${ }^{14}$

11 Tradução livre de: "this then is the living law in contradistinction to that which is being enforced in the courts and other tribunals. The living law is the which dominates life even though it has not been posited in legal propositions”. EHRLICH, Eugen. Fundamental Principles of the Sociology of Law. New York: Russel \& Russel - Inc, 1962. p. 493.

12 "Porque no es que la revolución transgrede una ley simplesmente, sino que la abroga y la destruye y la liquida por la acción explosiva de las fuerzas reprimidas que desencadena, para luego reemplezarla por otra, de conformidad con las nuevas demandas sociales a las que la revolución obedece. De lo qual se infiere que el objetivo principal de toda revolución es la supresión del orden juridico pré-existente y la sustitución por uno nuevo. Bien dice POVIÑA que 'la revolución lleva como objetivo proprio, la modificación del sistema de la organización del grupo'” BORJA, Rodrigo. Principios de Derecho Politico y Constitucional. Quito: Editorial Casa de la Cultura Ecuatoriana, 1964. p. 275.

13 Em apresentação de um sentido similar, desta revogação também nos fala A L Machado Neto, em seu livro "Sociologia Jurídica", quando escreve que "a mais importante das repercussões da revolução sobre o Direito Positivo consiste na revogação de todo o Direito anterior ou de parte dele pelo evento revolucionário". MACHADO NETO, A L. Sociologia Jurídica. São Paulo: Ed. Saraiva, 1973. p. 219.

${ }^{14}$ RAMALHETE, Clóvis. Revolução como fonte de direito: apontamentos de teoria jurídica das revoluções. In: Revista de informação legislativa, v. 11, n. 42, p. 99-114, abr./jun. 1974 | Revista da Faculdade de Direito da Universidade de Uberlândia, v. 6, n. 2, p. 127-145, 1977. Disponível em: https://www2.senado.leg.br/bdsf/item/id/180826. Acesso em: 21 out. 2021. 


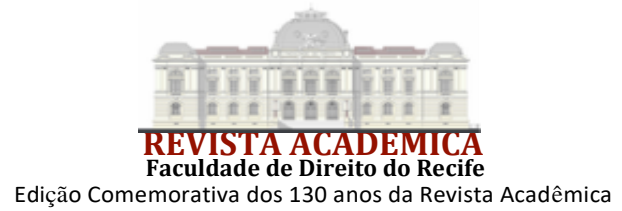

Observe-se que o fato de se tratar de substituição de uma ordem jurídica por outra (a ordem antiga pela nova $=$ revolucionária) não se opera de forma imediata ou abrupta. Nessa transformação, é possível identificar o Hiato ou ruptura Jurídico-Constitucional. ${ }^{15}$ Há um corte no ordenamento jurídico-constitucional que aos poucos será substituído por outro, embora neste período não deixem de existir, pelo menos, regras de transição ao lado de regras do Direito não legislado, costume, etc. ${ }^{16}$

Esse raciocínio será representado de forma gráfica, passando-se a explicá-lo de maneira didática nas linhas que seguem (Arte final de VENÍCIO DANTAS CAVALCANTI)

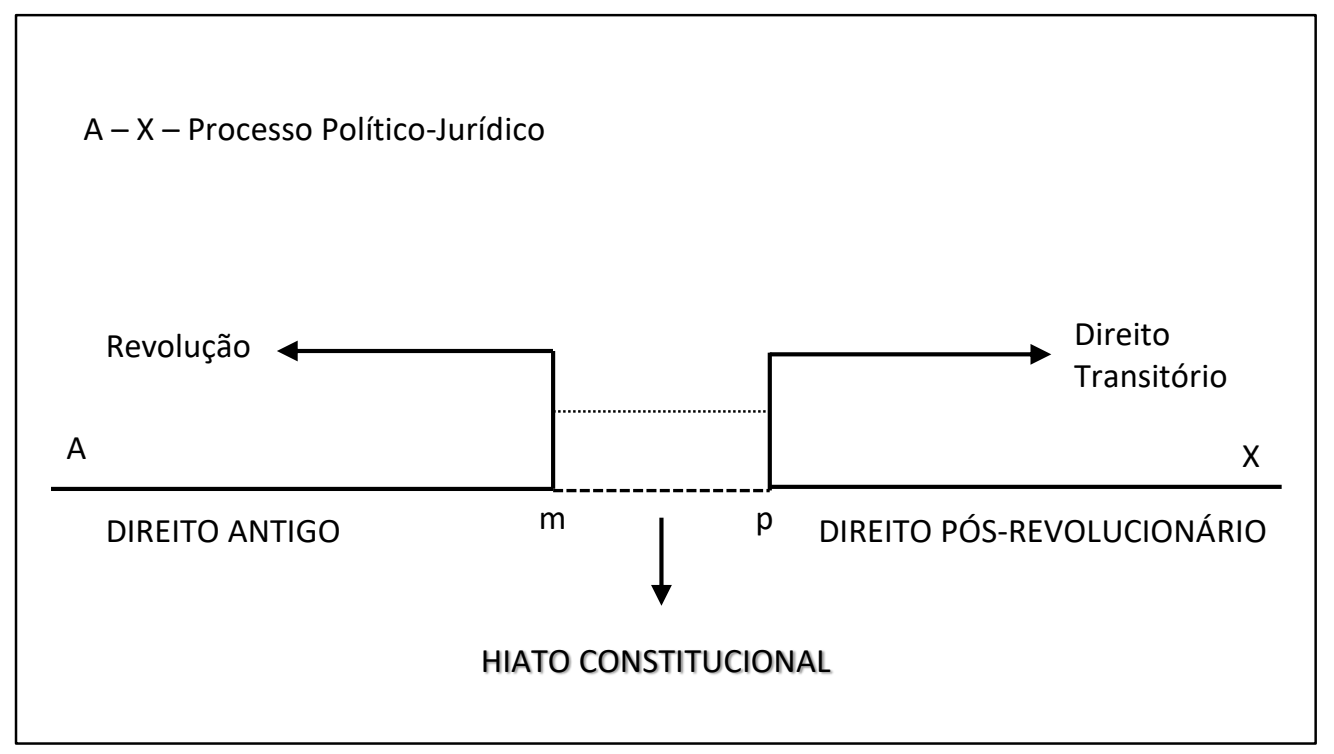

De início, observe-se que, na reta que compreende as letras A e X, que definimos como sendo o Processo Político-Jurídico, se encontram dois pontos de imensa importância: "m" e " $p$ ", o que faz surgir dois espaços, a saber: "A" "m" identificando o período do Direito Antigo, enquanto no segundo espaço "p" "X" voltamo-nos para o Direito Pós Revolucionário. O ponto "m" corresponde ao período da Revolução. No ponto "p" tem-se o início de aplicação do Direito Transitório.

Na faixa compreendida entre " $m$ " e " $p$ " encontra-se o período do Hiato Constitucional, durante o qual se governa através de Editos, Atos Institucionais etc., variando o vocábulo de acordo com o sistema constitucional.

Nessa fase de Hiato Constitucional, o movimento se vê formalmente retratado no que chamamos de Edito Revolucionário. ${ }^{17}$ A partir desse documento jurídico-positivo, poderemos identificar os objetivos e a linha do movimento vitorioso, além de sua tentativa de institucionalizar-

${ }^{15}$ A doutrina brasileira reconhece que a expressão "Hiato Constitucional” é criação de Ivo Dantas. Cf. DANTAS, Ivo. Poder Constituinte e Revolução. Breve introdução à Teoria Sociológica do Direito Constitucional. 2. ed. Bauru: Jalovi, 1985. A propósito, veja-se por todos, o que diz Pedro Lenza: “A expressão 'hiato constitucional' se deve a Ivo Dantas, quando desenvolveu o tema em sua dissertação de mestrado em 1976. Dantas analisa a relação entre o 'direito legislado', a 'Constituição política' e a "sociedade" ou "realidade social". O hiato constitucional, também chamado pelo autor de revolução, verifica-se quando há um choque (ou "divórcio") entre o conteúdo da Constituição política (uma das formas do direito legislado) e a realidade social ou sociedade" (LENZA, Pedro. Direito Constitucional Esquematizado. 22. ed. São Paulo: Saraiva Educação, 2018. p. 208).

${ }^{16}$ DANTAS, Ivo. Da Defesa do Estado e das Instituições Democráticas na Nova Constituição (Direito Constitucional de Crise ou de Legalidade Especial - arts. 136 a 44). Rio de Janeiro: Aidé Editora, 1989.

17 O substantivo "edito" tem duas formas de redação e sentidos: “edito" (paroxítono) significando "qualquer determinação legal", enquanto que "édito" (proparoxítona) equivale a "mandado judicial publicado em edital" (HOUAISS. Pequeno Dicionário Houaiss da Língua portuguesa. São Paulo: Moderna, 2015. p. 357). 


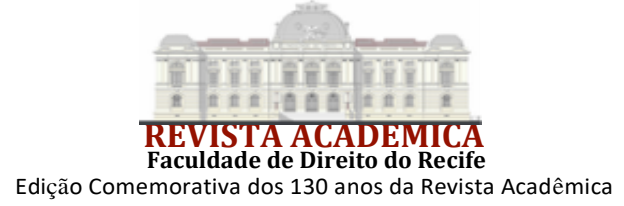

se e legislar, já que para as lideranças tudo foi feito em nome de um interesse maior - o interesse da comunidade -, em nome dos valores que se chocam com aqueles outros do ancien regime. ${ }^{18}$

Vale a pena que chamemos a atenção para um fato: a legislação surgida sob a forma de Edito Revolucionário não deve ser confundida com outorga, como, em hora oportuna, esclarece Ruy Ruben Ruschel no artigo "A Revolução e o Poder Constituinte". O autor estabelece que outorgar é "conceder, consentir, facultar, permitir, aprovar". Uma outorga constitucional competiria ao dono da soberania do Estado, correspondente a uma construção de soberania como um objeto de posse "individual, carismática e hereditária". Por sua vez, a promulgação revolucionária de novas normas fundamentais tem pressuposto doutrinário diverso. Os chefes se apresentam como guardiões do poder em nome do povo, em sua representação, não como titulares da soberania. 'O Edito Revolucionário não é, portanto, 'outorgado' à nação, mas 'editado' em nome da nação". ${ }^{19}$

$\mathrm{Na}$ época atual, as lideranças revolucionarias reconhecem que apenas são governantes (denominado de "Poder Institucionalizado", na lição de Burdeau) os agentes do Poder Constituinte, aos quais caberá, em nome da "nação", preparar a nova ordem jurídica, principalmente, a Constituição Política, entendida como "viga-mestra" da pirâmide jurídico-estatal. Com isso, busca-se a regulamentação positiva-formal dos valores sociais consagrados pela sociedade, base real sobre a qual deverão assentar-se os institutos jurídicos.

Estabelecida essa relação entre o Poder Constituinte e a Revolução, é necessário definir os contornos do Poder de Reforma (institucionalizado) na Constituição brasileira vigente, disposta para os períodos de normalidade constitucional, que é especificamente o objeto deste trabalho. A partir de um exercício hermenêutico sistemático, impõe considerar os limites dispostos pelo Poder Constituinte.

Essa consideração perpassa a análise dos aspectos formal e substancial. Esses aspectos trazem os meios indispensáveis ao exercício do Poder de Reforma, instrumentalizando a garantia da supralegalidade constitucional. Em síntese, o Poder de Reforma, porque constituído, une uma gama de limitações materiais e formais, que representa o núcleo de intocabilidade e de intangibilidade da Constituição vigente.

Paralelo a isso, a Constituição, como norma jurídica superior, frente a qual todo o ordenamento jurídico, negócios entre particulares, costumes e decisões judiciais e administrativas terão que se curvar, não está afastada da necessária constante adaptação aos novos valores sociais e políticos da sociedade para a qual foi elaborada. ${ }^{20}$

Em verdade, inexistem Constituições eternas e/ou imutáveis, como se chegou a falar no sec. XIX. Isso se deve a um fator: nenhuma sociedade é imutável e o Direito deve se modificar para não se condenar à ineficácia. Em sede constitucional, esse fator é instrumentalizado a partir da garantia da imutabilidade relativa, que protege a Constituição, através da autorização de que

18 Escreve A. L. Machado Neto que, em sendo a Revolução vitoriosa, o revolucionário deve pensar que a nova legislação, enquanto produto de uma Revolução que realizara em nome da Justiça, "é a expressão mais fiel do Direito natural tornado positivo pelo movimento revolucionário redentor". MACHADO NETO, A L. Sociologia Jurídica. São Paulo: Ed. Saraiva, 1973. p. 218.

19 RUSCHEL, Ruy Ruben. In: Revista da Escola de Direito da Universidade do Vale do Rio dos Sinos, São Leopoldo, RGS, v. 5, n. 13, p. 1, 1975.

20 Na famosa definição de Georges Burdeau, "poder é uma força a serviço de ideias". Para evitarmos interpretações errôneas, preferimos substituir o substantivo ideias por valores, visto que estes apontam mais para a direção do social, enquanto aquelas ficam mais no campo psicológico. Em sentido semelhante, Jean Dabin escreve: "Se ha hecho un estudio, desde el punto de vista filosófico, por las causas y los caracteres, del sistema del Estado. Era preciso comenzar por allí, porque el no es una 'cosa', sino una institución al servicio de una idea, la del bien público temporal, idea que responde, por lo demás, a exigências reales - de tendências y de necessidades susceptibles de constatación científica" (itálico no original). DABIN, Jean. Doctrina General del Estado Elementos de Filosofia Política. México: Editorial JUS, 1946. p. 163. 


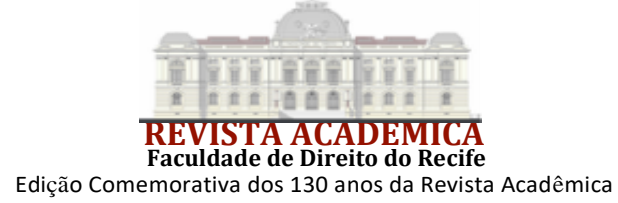

seja alterada pelo Poder de Reforma naquilo em que não fira a sua essência e na medida em que representa a atualização do texto à realidade.

As limitações ao Poder de Reforma não dispensam - mas obrigam - àqueles que têm competência para alterar a Constituição dentro da normalidade constitucional, estabelecendo que o faça através de uma das espécies do Poder de Reforma (Emenda à Constituição e Revisão), mediante técnica e em assuntos específicos, a partir de procedimento distinto dos que são utilizados para a produção do ordenamento infraconstitucional. O estudo da Revisão a que se dedica este trabalho parte da análise dos limites procedimentais estabelecidos no texto da Constituição vigente para essa espécie de ato do Poder de Reforma, conforme já indicado nas notas introdutórias.

Embora não seja o objeto deste trabalho se dedicar à apresentação genérica e pormenorizada de todos os limites que atingem o Poder de Reforma, neste ponto, é importante fazer referência a uma diferença profunda na aplicação deles. Os limites substanciais, com grande frequência, são passíveis de discussão doutrinária para se saber o real sentido do comando. Exemplifique-se com a disposição que veda a discussão para alterar a Constituição através de "emenda tendente a abolir a forma federativa de Estado" (CF, art. 60, § 4 , I e IV). Essa disposição dá margem a discussões acerca do que caracteriza o federalismo e a extensão de "direitos e garantias individuais". A definição do conteúdo das cláusulas pétreas precisa de maior esforço do intérprete. Por outro lado, os obstáculos procedimentais (inclusive temporais) que o texto constitucional cria às mudanças são mais claros, enumerados, minuciosamente descritos e, evidentemente, menos passíveis de discussões doutrinárias quanto à sua essência e limitação. ${ }^{21}$

Em suma, se, via de regra, as expressões de conteúdo material exigem maior trabalho do intérprete, o mesmo não ocorre com os limites formais, em que o caminho a ser percorrido na hipótese de exercício do Poder de Reforma está traçado de forma objetiva, restando-nos, simplesmente, verificar se na tramitação da proposta o cerimonial preestabelecido foi cumprido, ou não. Diante da violação ao seguimento cerimonial, caracteriza-se a inconstitucionalidade formal da Emenda e/ou Revisão que, em consequência, terá de ser rechaçada e repelida por infringir a Constituição a qual, embora permita que a matéria seja objeto de modificação, só a aceita dentro das diretrizes traçadas por ela própria.

O tema até então discorrido, situado na Teoria Geral do Direito Constitucional, foi apresentado com o intuito de trazer bases teóricas para efetivo enfrentamento do objeto deste trabalho. Antes de adentrar nele, no entanto, será feita uma análise do tema nas Constituições que serviram de inspiração para a brasileira.

\section{O TEMA EM ALGUMAS CONSTITUIÇÕES ESTRANGEIRAS: CONSTITUIÇÕES ITALIANA, ESPANHOLA E PORTUGUESA}

Até aqui discutimos o conceito científico estabelecido para as expressões "Poder Constituinte" e "Poder de Reforma", além de outros que se apresentaram insofismáveis. Conscientes da circulação de modelos ou da recepção legislativa, ${ }^{22}$ faremos uma incursão pelo Direito Constitucional Estrangeiro, a partir da transcrição de disposições dos textos da Constituição italiana, espanhola e portuguesa. ${ }^{23}$ Especificamente, limitar-nos-emos àqueles

${ }^{21}$ Aqui defendemos que as cláusulas consagradas no plebiscito de 1993, embora não sejam visíveis, funcionam como pétreas diante da opção feita pelo universo que por elas optou.

22 Cf. DANTAS, Ivo. Novo Direito Constitucional Comparado. Introdução, Teoria e Metodologia. 3. ed. Revista e atualizada. Curitiba: Juruá Editora, 2010.

23 O Direito Constitucional Estrangeiro se apresenta como um dos polos de estudo do Direito Comparado, não se identificando com ele. A análise da transcrição de disposições de direito estrangeiro perfaz um estudo muito mais superficial do que o realizado a partir do Direito Comparado. No Direito Comparado, teríamos de apontar as semelhanças e dessemelhanças entre as realidades estudadas. 


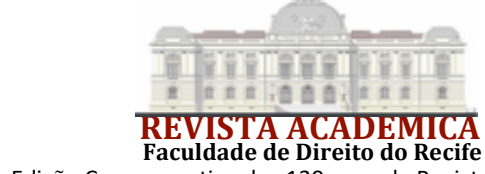

Edição Comemorativa dos 130 anos da Revista Acadêmica

sistemas jurídico-constitucionais que tiveram maior influência sobre o atual texto brasileiro de $1988,{ }^{24}$ representados pelas Constituições Italiana, Portuguesa e Espanhola. ${ }^{25}$

Comecemos pela Constituição Italiana de 1947. No Título VI, voltado à "Garanzie Costituzionali", após dedicar a "Sezione I" a "La Corte CostituzioPinali", estabeleceu nos arts. 138 e 139 (Sezione 1l) a "Revisione della Costituzione. Leggi Costituzionale", com o que se observa, de logo, que sob o ângulo da técnica legislativa, o constituinte italiano reconhecia que a garantia constitucional se assentava nos dois pilares referidos, quais sejam a existência de uma Corte Constitucional e a fixação de procedimentos modificadores do texto. Esses pilares seriam diferenciados daqueles voltados para a "Formazione delli Leggi" (arts. 70 e 77), este último tratando dos "decreti" con "valore di legge ordinaria", fonte direta de inspiração das "medidas provisórias" adotadas pela atual Constituição Brasileira de 1988 (art. 62). ${ }^{26}$

O segundo modelo, dentre os que mais influenciaram nossa Constituição, foi o Espanhol de 1978, por sua vez, até hoje com a redação modificada pela Reforma do art. 135, de 27 de setembro de 2011, a qual dedica o Título X e seus arts. 166 a 169 à Reforma Constitucional. Nos dispositivos mencionados, é visível que existe a consagração do poder de Reforma Constitucional em suas duas manifestações; como enunciação do mencionado Título X (gênero) e como espécie, através da previsão: "los proyectos de reforma constitucional deberán ser aprobados por una mayoría de tres quintos de cada una de las Cámaras". ${ }^{27}$

Por outro lado, o dispositivo mencionado ainda estabelece a exceção de que, quando for proposta a revisão total da Constituição ou uma parcial que afete alguns temas específicos dispostos no texto, procederá uma aprovação por maioria qualificada de cada Câmara e a dissolução imediata das Cortes. ${ }^{28}$

Em uma leitura atenta do texto constitucional espanhol, verifica-se que o texto não limita o número de revisões, ao tempo em que consagra a forma procedimental de ambas as hipóteses, conforme transcrição literal, inclusive em sua formatação:

\section{Título X De la reforma constitucional}

\section{Artículo 166}

La iniciativa de reforma constitucional se ejercerá en los términos previstos en los apartados 1 y 2 del artículo 87. ${ }^{29}$ Artículo 167 1. Los proyectos de reforma constitucional

${ }^{24}$ Claro que não foram apenas estes os modelos constitucionais que influenciaram o nosso texto, como demonstra Ana Lúcia De Lyra Tavares, no artigo A Constituição Brasileira de 1988: subsídios para os comparatistas. In: Revista de informação legislativa, v. 28, n. 109, p. 71-108, jan./mar. 1991. Disponível em: http://www2.senado.leg.br/bdsf/handle/id/175845. Acesso em: 20 out. 2021. Neste sentido, pode-se dizer que "nossa Constituição é uma inveterada devedora".

${ }^{25}$ A enumeração destes três modelos constitucionais está adotando o critério cronológico. Não significa, contudo, que fiquemos rigidamente a eles aprisionados sendo até possível que outras referências sejam trazidas à colação.

${ }^{26}$ Cf. DANTAS, Ivo. Aspectos Jurídicos das Medidas Provisórias. 3. ed. Revista e aumentada. Brasília: Brasília Jurídica Editora, 1997 (livro pioneiro na literatura nacional).

27 Em tradução livre: "os projetos de reforma constitucional deverão ser aprovados por uma maioria de três quintos de cada uma das Câmaras".

28 “cuando se propusiere la revisión total de la Constitución o una parcial que afecte al Título preliminar, al Capítulo segundo, Sección primera del Título I, o al Título II, se procederá a la aprobación del princípio por mayoría de dos tercios de cada Cámara, y a la disolución inmediata de las Cortes."

29 Artículo 871. La iniciativa legislativa corresponde al Gobierno, al Congreso y al Senado, de acuerdo con la Constitución y los Reglamentos de las Cámaras. 2. Las Asambleas de las comunidades Autónomas podrán solicitar del Gobierno la adopción de un proyecto de ley o remitir a la Mesa del Congreso una proposición de ley, delegando ante dicha Cámara un máximo de tres miembros de la Asamblea encargados de su defensa. 3. Una ley orgánica regulará las formas de ejercicio y requisitos de la iniciativa popular para la presentación de proposiciones de ley. En todo caso se exigirán no menos de 500.000 firmas acreditadas. No procederá dicha iniciativa en materias propias de ley orgánica, tributarias o de carácter internacional, ni en lo relativo a la prerrogativa de gracia. 
deberán ser aprobados por una mayoría de tres quintos de cada una de las Cámaras. Si no hubiera acuerdo entre ambas, se intentará obtenerlo mediante la creación de una Comisión de composición paritaria de Diputados y Senadores, que presentará un texto que será votado por el Congreso y el Senado. 1. De no lograrse la aprobación mediante el procedimiento del apartado anterior, y siempre que el texto hubiere obtenido el voto favorable de la mayoría absoluta del Senado, el Congreso, por mayoría de dos tercios, podrá aprobar la reforma. 3. Aprobada la reforma por las Cortes Generales, será sometida a referéndum para su ratificación cuando así lo soliciten, dentro de los quince días siguientes a su aprobación, una décima parte de los miembros de cualquiera de las Cámaras. Artículo 168. Cuando se propusiere la revisión total de la Constitución o una parcial que afecte al Título preliminar, al Capítulo segundo, Sección primera del Título I, o al Título II, se procederá a la aprobación del princípio por mayoría de dos tercios de cada Cámara, y a la disolución inmediata de las Cortes. 2. Las Cámaras elegidas deberán ratificar la decisión y proceder al estudio del nuevo texto constitucional, que deberá ser aprobado por mayoría de dos tercios de ambas Cámaras. 3. Aprobada la reforma por las Cortes Generales, será sometida a referéndum para su ratificación. Artículo 169. No podrá iniciarse la reforma constitucional en tiempo de guerra o de vigencia de alguno de los estados previstos en el artículo 116.

Por sua vez, a Constituição da República Portuguesa de 1997, ${ }^{30}$ inclusive com a revisão de 1989, seguindo a técnica do texto italiano, dedica a sua Parte IV à "Garantia e Revisão da Constituição", esta última regulada nos arts. $284^{\circ}$ a $289^{\circ}$, enquanto pela Constituição Espanhola de 1978, no Título X, se trata "De la Reforma Constitucional" (artículos 166 a 169). Textualmente, prescreve a Constituição Portuguesa:

\section{Revisão constitucional}

Artigo 284. ${ }^{\circ}$ (Competência e tempo de revisão). 1. A Assembleia da República pode rever a Constituição decorridos cinco anos sobre a data da publicação da última lei de revisão ordinária. 2. A Assembleia da República pode, contudo, assumir em qualquer momento poderes de revisão extraordinária por maioria de quatro quintos dos Deputados em efectividade de funções.

Artigo 285. (Iniciativa da revisão). 1. A iniciativa da revisão compete aos Deputados. 2. Apresentado um projecto de revisão constitucional, quaisquer outros terão de ser apresentados no prazo de trinta dias.

Artigo 286. (Aprovação e promulgação). 1. As alterações da Constituição são aprovadas por maioria de dois terços dos Deputados em efectividade de funções. 2. As alterações da Constituição que forem aprovadas serão reunidas numa única lei de revisão. 3. O Presidente da República não pode recusar a promulgação da lei de revisão.

Artigo 287. (Novo texto da Constituição). 1. As alterações da Constituição serão inseridas no lugar próprio, mediante as substituições, as supressões e os aditamentos necessários. 2. A Constituição, no seu novo texto, será publicada conjuntamente com a lei de revisão.

Artigo 288. (Limites materiais da revisão)

As leis de revisão constitucional terão de respeitar: a) A independência nacional e a unidade do Estado; b) A forma republicana de governo; c) A separação das Igrejas do Estado; d) Os direitos, liberdades e garantias dos cidadãos; e) Os direitos dos trabalhadores, das comissões de trabalhadores e das associações sindicais; f) A coexistência do sector público, do sector privado e do sector cooperativo e social de propriedade dos meios de produção; g) A existência de planos económicos no âmbito de uma economia mista; h) O sufrágio universal, directo, secreto e periódico na designação dos titulares electivos dos órgãos de soberania, das regiões autónomas e do poder local, bem como o sistema de representação proporcional; i) $\mathrm{O}$ pluralismo de expressão e organização política, incluindo partidos políticos, e o direito de oposição democrática; j) A separação e a interdependência dos órgãos de soberania; 1) A fiscalização da constitucionalidade por acção ou por omissão de normas jurídicas; m) A independência dos tribunais; n) A autonomia das autarquias locais; o) A autonomia políticoadministrativa dos arquipélagos dos Açores e da Madeira. 


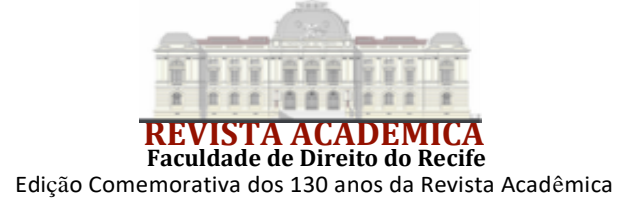

Artigo 289. ${ }^{\circ}$ (Limites circunstanciais da revisão). Não pode ser praticado nenhum acto de revisão constitucional na vigência de estado de sítio ou de estado de emergência.

Verifica-se, da leitura da Constituição Lusa, que foram consagradas duas formas ou tipos de revisão, a saber: (i) a revisão ordinária, depois de cinco anos da última realizada e (ii) a revisão extraordinária, a ser feita a qualquer momento, desde que seja requerida por $4 / 5$ dos Deputados em efetivo exercício da função. No art. 288 da CRP, estabelecem-se os limites materiais a que tem o poder de respeitar como limites materiais à revisão.

Além destas, inúmeras outras Constituições seguem o mesmo comportamento quanto à localização do Poder de Reforma, podendo-se fazer referência à Constituição da França (1958), Título XIV, "De la Revision", art. 89; à Constituição Política do Peru (12.7.79), Título VI, "Reforma de Ia Constitución", art. 306; e à Constituição da Grécia (9.6.75), 4ª Parte, "Disposições Finais e Transitórias", Seção B, art. 10.

\section{O PROBLEMA NA CONSTITUIÇÃO BRASILEIRA: REVISÃO E EMENDA. ART. $3^{\circ}$ DO ATO DAS DISPOSIÇÕES CONSTITUCIONAIS TRANSITÓRIAS. A APLICAÇÃO DOS CONCEITOS}

$\mathrm{O}$ art. $3^{\circ}$ do Ato das Disposições Constitucionais Transitórias (ADCT) prevê a Revisão, estabelecendo que "a revisão constitucional será realizada após cinco anos, contados da promulgação da Constituição, pelo voto da maioria absoluta dos membros do Congresso Nacional, em sessão unicameral", no que, sem dúvida, e com alguma pequena diferença, inspirou-se no art. 286-1 da citada Constituição portuguesa de 1976. ${ }^{31} \mathrm{O}$ tratamento dispendido à Emenda, por sua vez, foi posto no art. 59, I, e 60 do corpo permanente da CRFB/88.

A inserção da Emenda à Constituição como espécie de processo legislativo é formato de disposição que, no histórico das Constituições brasileiras, consubstancia grande inovação. Na história constitucional brasileira, foi com o texto de 1967 que a previsão de mudança constitucional formal passou a constar inserida no denominado processo legislativo (art. 47), já que até a Constituição de 1946 o tratamento oferecido à matéria era diferente. A Carta de 1824 (arts. 174/177), a Constituição de 1891 (art. 90) e a Constituição de 1934 (art. 178) tratavam a mudança da Constituição em suas Disposições Gerais; ${ }^{32}$ em 1937, a Carta do Estado Novo dedicou-lhe o art. $174\left(\S \S 1^{\circ} \mathrm{a} 4^{\circ}\right)$, sob a denominação de Emendas à Constituição, precedendo às Disposições Transitórias e Finais, enquanto a Constituição de 1946 (art. 217) voltou a incluí-la nas Disposições Gerais.

Essa confusão existente no histórico brasileiro, ora separando ora nem mencionando todos os atos de Poder de Reforma, faz necessário enfrentar se Emenda e Revisão são espécies sinonímicas ou se há uma diferença substancial no conteúdo dos termos.

A partir de uma análise da etimologia das palavras envolvidas, tem-se que não há diferença entre os termos "Emenda", "Reforma" e "Revisão". ${ }^{33}$ Trazendo para a experiência

31 A Constituição portuguesa só se refere a uma revisão. Vale a repetição do Artigo 284. ${ }^{\circ}$ (Competência e tempo de revisão) da Constituição Portuguesa: "1. A Assembleia da República pode rever a Constituição decorridos cinco anos sobre a data da publicação da última lei de revisão ordinária. 2. A Assembleia da República pode, contudo, assumir em qualquer momento poderes de revisão extraordinária por maioria de quatro quintos dos Deputados em efectividade de funções".

32 Pelo texto de 1824, o título era "Das Disposições Gerais e Garantias dos Direitos Civis e Políticos dos Cidadãos Brasileiros".

33 "Emendar: vt. Corrigir, reformar, ligar uma cousa a outra. Lat. emendare. Deriv.: emenda, s.f., correção, reparo, deverbal de emendar, emendação, s.f., ato de emendar, lat. emmendationem; emendador, adj., que emenda, lat. emendatorem; emendatriz, lat. emendatricem; emendatório, lat. emendatorius; emendável, lat. emendabilis. Revisão: s.f. leitura atenta de um escrito para exprimir-lhe os erros, os enganos de impressão, os "gatos". Exame de um escrito ou de uma situação para corrigir os erros. Lat.: revisio, onis". BUENO, Silveira. Grande Dicionário 
jurídica, Rosah Russomano, ao estudar as Emendas à Constituição no livro "Dos Poderes Legislativo e Executivo", estabelece que Revisão e Reforma seriam atos equivalentes. O autor ainda destaca que, para parcela da doutrina, na mesma medida, haveria equivalência entre Revisão, Reforma e Emenda. ${ }^{34}$ Outros autores apresentam pensamentos semelhantes. ${ }^{35}$

Num sentido diverso, Nelson de Souza Sampaio, dispõe que a Emenda seria dado que exsurge do estudo da amplitude da Reforma, consubstanciando uma Reforma parcial da Constituição. A Revisão, nessa conjuntura, seria uma espécie de Reforma total. ${ }^{36}$

A aplicação vertiginosa dos três termos - Reforma, Emenda e Revisão - foi alvo de crítica assinada por José Afonso da Silva. O autor destaca que, mesmo existindo uma tendência à disposição da Reforma como gênero de todos os métodos de mudança da Constituição, "para englobar todos os métodos de mudança formal das constituições, que se revelam especialmente mediante o processo de emenda e o procedimento de revisão", ainda é comum o emprego indiferente dos termos. ${ }^{37}$

Adiante em suas críticas, o autor fez uma afirmação dedicada ao texto constitucional de 67-69, mas que se aplica, perfeitamente, ao texto vigente de 1988. Indicou que, a Emenda se anexaria ao texto com numeração de origem, enquanto a Revisão se incorporaria ao próprio texto, tal qual previsto na Constituição de 1934, cuja Constituição de 1946 distinguia expressivamente. ${ }^{38}$ Esta última afirmativa de José Afonso, permite-nos uma observação que não invalida sua colocação, mas serve para mostrar o condicionamento da época sobre a Teoria Constitucional: a Emenda de 1926 à Constituição de 1891, incorporou-se ao texto original, como nos moldes do processo revisional, sem que, com isto, tenha ficado anexado ao texto.

De volta ao centro do ponto que ora analisamos, e sobre o qual, apesar de Rosah Russomano entender tratar-se de "minúcias filigranadas", assim não nos parece. Principalmente se, ao lado do debate teórico e doutrinário, pretendermos enfrentar a questão referida no título deste trabalho e relacionada ao atual momento constitucional brasileiro, em que a possibilidade de exercício do Poder de Reforma é constantemente utilizado como manobra política.

Não poderíamos encerrar este levantamento doutrinário sem que apresentássemos a posição do clássico e sempre atual Luiz Pinto Ferreira, pioneiro em inúmeros estudos de Direito Constitucional, como o que deu origem ao livro "Princípios Gerais do Direito Constitucional

Etimológico-Prosódico da Língua Portuguesa. São Paulo: Ed. Lisa S/A - Livros Radiantes, 1968, v. 3, p. 1086 e v. 7, p. 3528, respectivamente.

34 "A designação que se lhes dá é a de revisão ou reforma tidas, por uma corrente do pensamento jurídico, como expressões sinônimas. A revisão ou reforma, tal como acentua PONTES DE MIRANDA, pode, porém, ser total ou parcial. No primeiro caso, há mudanças de todas as regras jurídicas constitucionais. No segundo, o Poder Reformador só é apto a mudar alguma ou algumas regras jurídicas. À reforma parcial, via de regra, imprime-se a designação de emenda. Para outra corrente do pensamento, porém, há sinonímia, não só entre os termos revisão e reforma, como também entre estas e a expressão emenda". RUSSOMANO, Rosah. Dos Poderes Legislativo e Executivo. Rio de Janeiro: Livraria Freitas Bastos S/A, 1976. p. 131.

35 Na mesma linha de raciocínio, Alcino Pinto Falcão, em sua Constituição Anotada afirma: "Essa questão é tãosomente de nomenclatura, não modifica a substância e não significa nada quanto ao alcance do poder de reforma. O problema se apresenta também para os norte-americanos; o respectivo artigo V só se refere a amendment, mas a doutrina esclarece que o termo abrange as revisions". FALCÃO, Alcino Pinto. Constituição Anotada. São Paulo: José Konfino Editor, 1957. v. 3, p. 232-233).

36 "Quanto à sua amplitude, costuma-se falar em reforma total e reforma parcial da Constituição. O termo emenda tem maior propriedade nesta última hipótese, mas é usado também no sentido amplo como equivalente de revisão ou reforma, como fazem os escritores ingleses com as expressões amendment e revisions de referência a alterações da Constituição" SAMPAIO, Nelson de Souza. O Poder de Reforma Constitucional. Salvador: Livraria Progresso Editora, 1954. p. 83.

37 DA SILVA, José Afonso. Reforma Constitucional. Revista Trimestral de Jurisprudência dos Estados, São Paulo: Jurid Vellenich, , p. 14, 1980.

38 Op. cit. 


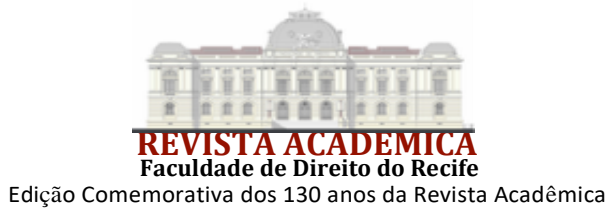

Moderno", que traz uma apresentação dos princípios que só recentemente passou a ser alcançada. $39-40$

Ensina Pinto Ferreira que a técnica jurídica das constituições admite duas hipóteses de mudança formal das leis fundamentais do Estado, quais sejam a Emenda e a Revisão, sendo a Reforma o gênero desses subtipos. A Emenda seria "a modificação de certos pontos, cuja estabilidade o legislador constituinte não considerou tão grande como outros mais valiosos, se bem que submetidos a obstáculos e formalidades mais difíceis que os exigidos para a alteração das leis ordinárias". A Revisão, por sua vez, seria "uma alteração anexável, exigindo formalidades e processos mais lentos e com mais dificuldade, que a emenda, a fim de garantir uma suprema estabilidade ao texto constitucional". ${ }^{41}$

Embora a etimologia das palavras em análise tenha apresentado uma espécie de sinonímia entre os três verbetes, à luz da Constituição de 1988 é possível indicar que não se diz o mesmo sobre o sentido jurídico dessas palavras. Parece-nos que a intenção do legislador constituinte ficou bem clara, criando duas situações distintas, embora em ambas, a competência seja própria do Poder Constituído - o Poder de Reforma.

A nossa Constituição vigente insere o tema da Emenda no corpo permanente da Constituição e a Revisão no seu Ato das Disposições Constitucionais Transitórias. O art. 59, I, da CRFB/88 dispõe a Emenda como espécie de processo legislativo, regulamentando-a no dispositivo seguinte. Para ela, foi estabelecida uma ritualística detalhada, trazendo um quórum específico até para propô-la, indicando um rol restrito de legitimados. ${ }^{42}$ Também são indicadas circunstâncias em que é vedado alterar o texto, como diante de intervenção federal, de estado de defesa e de estado de sítio ( $\$ 1^{\circ}$ do art. 60$)$. O dispositivo ainda determina que a proposta de emenda tem que ser discutida e votada em cada Casa do Congresso Nacional, em dois turnos, considerando-se aprovada se obtiver, em ambos, três quintos dos votos dos respectivos membros ( $\$ 2^{\circ}$ do art. 60).

Da forma como foi elaborada, a Emenda tem âmbito restrito, atingindo apenas alguns artigos, incisos ou alíneas, sem poder alcançar grande parte do texto de uma só vez, que, contudo, poderá ser alvo de tantas emendas quantas sejam necessárias no entender do legislador ordinário, que terá de enfrentar dificuldades como, por exemplo, o quórum bem mais alto do que no caso de Revisão.

A Revisão, por sua vez, tem seu procedimento fixado de maneira superficial, indicando a exigência de voto da maioria absoluta dos membros do Congresso Nacional, em sessão unicameral, exigências bem mais fáceis de serem atendidas (art. $3^{\circ}$, ADCT). O Constituinte, conscientemente, facilitou a Revisão frente à Emenda. Aquela, por outro lado, tende a ser ampla, abrangente, podendo atingir a Constituição como um todo de uma só vez.

Diante desses aspectos procedimentais, já é possível indicar que as expressões em si mesmas não têm o mesmo sentido jurídico-constitucional. A Constituição não estabeleceria graus de exigência diferentes para a mesma coisa. Essa diferenciação, por sua vez, não poderia ser de

39 FERREIRA, Luiz Pinto. Princípios gerais do Direito Constitucional moderno. 6. ed. São Paulo: Saraiva, 1983. p. 679694. v. 2.

40 Destaque se que o fato de termos citado uma edição de 1983 em nada prejudica, pois, poucos anos depois, em 1994, o autor publicou o até então mais completo estudo monográfico no Brasil. FERREIRA, Luiz Pinto. A Constituição e o Poder de Reforma Constitucional (Revisão e emenda). 3. ed. Recife: Faculdade de Ciências Humanas de Pernambuco. Sociedade Pernambucana de Cultura e Ensino. 1994. A 1a edição foi escrita em 1946, como Tese ao Concurso de Livre Docente à Faculdade de Direito do Recife, não chegando a ser defendida, visto que logo depois foi aberto o concurso à cátedra de Direito Constitucional, fato que ficou na História da UFPE.

41 Op. cit., p. 88.

42 Art. 60, da CRFB/88. A Constituição poderá ser emendada mediante proposta:

I - de um terço, no mínimo, dos membros da Câmara dos Deputados ou do Senado Federal;

II - do Presidente da República;

III - de mais da metade das Assembléias Legislativas das unidades da Federação, manifestando-se, cada uma delas, pela maioria relativa de seus membros. 


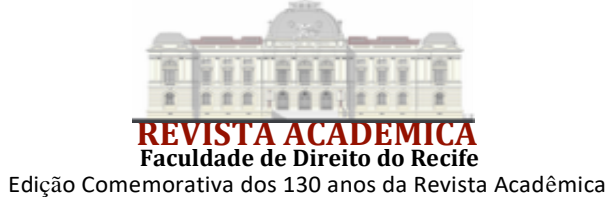

cunho material, pois todo o Poder de Reforma está submetido ao núcleo de intangibilidade ( $\$ 4^{\circ}$ do art. 60 da CRFB/88).

Aqui é importante comentar que, embora seja um dado, a amplitude da modificação não se apresenta como um fator decisivo para diferenciar as espécies de ato de Poder de Reforma. Se o Poder de Reforma atuou em uma parte ou em diversas partes do documento, pouco importa em termos práticos, podendo-se utilizar da Emenda ou da Revisão. Lembremo-nos do texto constitucional de 1967, alterado em 1969 em quase a sua totalidade e, no entanto, foi denominada de Emenda Constitucional n. 1/69. ${ }^{43}$

Estabelecidas as diferenças procedimentais entre Revisão e Emenda, é importante enfrentar qual método interpretativo é mais adequado para compreender a extensão dada pelo Constituinte à Revisão constitucional. $\mathrm{O}$ art. $3^{\circ}$ do $\mathrm{ADCT}$ estabelece que "a revisão constitucional será realizada após cinco anos, contados da promulgação da Constituição". O art. $2^{\circ}$ do ADCT ainda estabelecia que, em 07/09/1993, o eleitorado, através de plebiscito, teria que definir a forma e o sistema de governo a serem adotados.

Destaque-se que a fixação de prazo para realização da Revisão não impedia que fosse realizada Emenda à Constituição no ínterim respectivo, ${ }^{44}$ fator que também demonstra a existência de diferença e a autonomia entre os tipos. Acaso o Constituinte pretendesse que indicasse limitação temporal, tê-lo-ia estabelecido de forma expressa, como o fez, por exemplo, na Constituição Francesa de 1791 no art. $1^{\circ}$ do seu Título VII, ${ }^{45}$ bem como na Constituição da Síria (1950, 2 anos), do Equador (1929, 4 anos), do Paraguai (1970, 5 anos) e da Espanha, 1812. ${ }^{46}$

Em nosso entender, a fixação estabelecida pelo art. $2^{\circ}$ do Ato das Disposições Constitucionais Transitórias para que, no dia 7 de setembro de 1993 o eleitorado definisse, ${ }^{47}$ por meio de plebiscito, a forma (república ou monarquia constitucional) e o sistema de governo (parlamentarismo ou presidencialismo) que deveriam vigorar no País, tem em si dois pontos a serem destacados: (i) estabelece uma situação concreta na qual (a soberania popular seria exercida pelo sufrágio direto" (art. 14), mediante o plebiscito (art. 14-I); (ii) destaca um aspecto que poderia passar despercebido: a República e a Federação, que desde a Constituição de 1891 até o texto de 67/69 apareciam como cláusulas pétreas, deixaram de ser indicadas como tal.

Fixando o Constituinte a data de 07/09/93, o que se pode deduzir é que esta seria obrigatoriamente aquela em que a matéria deveria ser apreciada, não apenas pelo Congresso Nacional no exercício do Poder Reformador, mas pelo eleitorado, por meio de uma intervenção direta e cujo resultado vincularia, obrigatoriamente, o tratamento da matéria na Revisão constitucional a ser realizada após cinco anos da promulgação do texto hoje vigente.

Note-se um importante detalhe: a Revisão, tendo de ser realizada após 5 (cinco) anos, só seria levada a efeito após 5 de outubro de 1993, portanto, quando já se teria realizado o plebiscito (21/04/93, ver nota de rodapé 43). Embora a redação do texto mostre que, enquanto a manifestação popular tinha data certa (21/04/93), a Revisão tinha uma data mínima (5/10/93). Nesse sentido, o resultado da consulta plebiscitária vincula o conteúdo da Revisão.

Embora tenham sido feitas poucas exigências procedimentais à realização da Revisão, de certo modo facilitando a sua feitura, a amplitude que possui e o fato de se tratar de espécie de Reforma diz-nos que deve ser realizada com muita temperança. Alerta Pedro Lessa que, diante situações aflitivas, surgem inúmeros terapeutas sociais para sugerir um único remédio: a Reforma

43 Para nós, o texto de 67/69 não deve ser denominado nem de Carta Política, nem Constituição, em razão de sua origem. Preferimos denominar de o Pacto Constitucional de 67/69, inspirado no modelo inglês de 1215.

44 Nesse período, foram aprovadas as seguintes emendas: a ponto de terem sido aprovadas as de $n=1$ (31.3.92), $n$ 은 2 (25.8.92), no 3 (17.3.93) e no 4 (14.9.93).

45 "La prochaine Législature et la suivante ne pourront proposer la réforme d'aucun article constitutionnel".

46 Art. 375: "Hasta pasados ochos años después de hallarse puesta en práctica la Constitución en todas sus partes, no se podrá proponer alteración, adición ni riforma en ninguno de sus artículos".

47 Pela EC no 2 (25.8.92) foi o plebiscito antecipado para 21.4.93. 


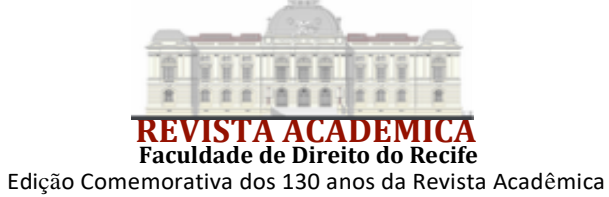

da Constituição. O autor ainda destaca que, para aqueles que se habituaram a estudar pela observação histórica e pela comparação dos fatos sociais, inexistiria medicação mais falha, mais negativa. "As reformas constitucionais são os recursos predilectos das nações fracas, incapazes por sua falta de educação e de energia - de um bom governo practico" e também de "nações decadentes e enervadas, que, umas e outras appellam frequentemente, mas debalde, para tão desacreditada panacéa". ${ }^{48}$

\section{CONSIDERAÇÕES FINAIS}

Diante da narrativa construída, é possível indicar que o Poder de Reforma deve ser exercido para atender às novas estruturas sociais e jurídicas, tendo ampla e profunda conexão com as valores e ideias políticas de cada momento. Diante de uma nova realidade, a permissão à alteração do texto constitucional, não corresponde a um "cheque em branco" que tudo permite, pois deve ser feita em atenção aos limites impostos na própria Constituição. A imutabilidade relativa, enquanto garantia da Constituição, indicia uma lógica interpretativa restritiva, de modo que a possibilidade de relativização da imutabilidade deve encontrar previsão clara na Constituição.

Enquanto espécies de ato do Poder de Reforma, o texto da Constituição de 1988 traz uma diferença clara entre Emenda e Revisão Constitucional. A Emenda se destina a uma reforma pontual da Constituição. A Revisão, por sua vez, tem um sentido mais amplo, podendo atingir toda a Constituição. ${ }^{49}$

Os limites materiais são comuns aos atos de Reforma. Mas a diferença conceitual fez com que o Constituinte fixasse um procedimento desigual para cada ato, trazendo mais exigências para a primeira espécie (Emenda), a fim de evitar a multiplicação de alteração da Constituição. Como pode ser realizada com mais frequência, foi inserida no texto permanente da Constituição. A Revisão, por sua vez, foi inserida junto às disposições transitórias, o que indicia que foi prevista para verificar a transição, e com baixa exigência procedimental para alteração.

Em verdade, a insistência de alguns partidos e grupos de poder no sentido de uma nova Revisão da Constituição de 1988, no fundo, visa aproveitar as facilidades do processo revisor, para descaracterizar-se o texto constitucional. Nesse propósito, alguns trabalham com o argumento de que a Revisão não se submete às Cláusulas Pétreas e, portanto, os Direitos e Garantias Individuais (art. 60, $\S 4^{\circ} \mathrm{IV}$ ) poderiam ser diminuídos ou até retirados, sobretudo, os Sociais e Trabalhistas.

Nós temos sempre que saber, com precisão, quantas almas tem a Constituição. E se ela tem alma, não deve ter calma para reagir a cada investida que lhes arranca a identidade. A Constituição, ao definir os contornos do Poder de Reforma, se lê alheia, compondo letras que protegem o seu ser. Em nenhum momento pode ser relida e questionar-se "Fui eu?". ${ }^{50}$ Essa dúvida, oriunda de uma crise de identidade constitucional, põe em xeque elemento insofismável à ordem jurídica, indiciando a existência de uma fraude constitucional.

Concluindo, deixemos bem clara nossa posição: embora prevista no texto permanente da CF a figura da Revisão está limitada a uma única Revisão, enquanto a Emenda não está limitada quanto ao número de vezes. Ambas estão limitadas aos limites da e conteúdo do texto constitucional.

\section{REFERÊNCIAS}

48 LESSA, Pedro. Reforma Constitucional. Rio de Janeiro: Editora Brasileira Lux, s/d, p. 3-4.

49 Na exposição que fizemos na Defesa de Tese de DOUTORADO - UFMG, 1990, intitulada Do Poder de Reforma como garantia da Supralegalidade Constitucional (mimeo), oportunidade em que fomos contestado por RAUL MACHADO HORTA, que segundo suas palavras "respeitava nossa posição".

${ }^{50}$ Referência ao poema de Fernando Pessoa, "Não sei quantas almas tenho", que foi referendado na introdução do trabalho. 
BORJA, Rodrigo. Principios de Derecho Politico y Constitucional. Quito: Editorial Casa de la Caultura Ecuatoriana, 1964.

BRINTON, Crane. Anatomia de la Revolución. Mexico: Fundo de Cultura Economica, 1942.

BRUHL, Henri L. Sociologia del Derecho. Buenos Aires: Ed. Universitária, 1971.

BUFFELAN, Jean P. Introduction a la sociologie Politique. Paris: Masson Et Cie. Edteurs, 1969.

BURDEAU, Georges. Droit Constitutionnel et Institutions Politiques. 6. ed. Paris: LGDJ, 1974.

BURDEAU, Georges. Traité de Science Politique. 10. ed. Paris: Librairie Générale de Droit et de Jurisprudence, 1969. t. 4.

BURDEAU, Georges. L'état. Paris: Ed. Du Seuil, 1970.

BURDEAU, Georges. Método de la Ciencia Política. Buenos Aires: Ed. Depalma, 1964.

CAMPOS, Bidart. Filosofia del Derecho Constitucional. Buenos Aires: Ediar, 1969.

CAMPOS, Bidart. Lessiones Elementales de Política. Buenos Aires: Ediar, 1973.

DABIN, Jean. Doctrina General del Estado: Elementos de Filosofia Política. México: Editorial JUS, 1946.

DANTAS, Ivo. Aspectos Jurídicos das Medidas Provisórias. 3. ed. Brasília: Brasília Jurídica Editora, 1997.

DANTAS, Ivo. Da Defesa do Estado e das Instituições Democráticas na Nova Constituição (Direito Constitucional de Crise ou de Legalidade Especial - arts. 136 a 44). Rio de Janeiro: Aidé Editora, 1989.

DANTAS, Ivo. Poder Constituinte e Revolução. Breve introdução à Teoria Sociológica do Direito Constitucional. 2. ed. Bauru: Jalovi, 1985.

DANTAS, Ivo. Instituições de Direito Constitucional Brasileiro. 3. ed. Curitiba: Juruá Editora, 2014.

DANTAS, Ivo. Novo Direito Constitucional Comparado. Introdução, Teoria e Metodologia. 3. ed. Curitiba: Juruá Editora, 2010.

DANTAS, Ivo. Teoria do Estado Contemporâneo. 3. ed. Curitiba: Juruá Editora, 2016.

DA SILVA, José Afonso. Reforma Constitucional. Revista Trimestral de Jurisprudência dos Estados, São Paulo: Jurid Vellenich, 1980.

DUVERGER, Maurice. Introducción a la Política. Barcelona: Ed. Ariel, 1970. 
EHRLICH, Eugen. Fundamental Principles of the Sociology of Law. New York: Russel \& Russel - Inc, 1962.

FERREIRA, Pinto. Princípios Gerais do Direito Constitucional Moderno. São Paulo: Saraiva, 1962.

FERRERO, Guglielmo. EI Poder. Los Genios Invisibles de la Ciudad. Buenos Aires: Ed. InterAmericana, 1943.

HOUAISS. Pequeno Dicionário Houaiss da Língua portuguesa. São Paulo: Moderna, 2015.

LESSA, Pedro. Reforma Constitucional. Rio de Janeiro: Editora Brasileira Lux, s/d.

LIMA, Getúlio T. Reflexão sobre o poder constituinte. In: Estudos Jurídicos, RGS, v. 5, n. 13, 1975.

MACHADO NETO, A L. Sociologia Jurídica. São Paulo: Ed. Saraiva, 1973.

RAMALHETE, Clóvis. Revolução como fonte de direito: apontamentos de teoria jurídica das revoluções. Revista de informação legislativa, v. 11, n. 42, p. 99-114, abr./jun. 1974.

REVISTA DA FACULDADE DE DIREITO DA UNIVERSIDADE DE UBERLÂNDIA, v. 6, n. 2, p. 127-145, 1977. Disponível em: https://www2.senado.leg.br/bdsf/item/id/180826. Acesso em: 21 out. 2021.

REIS, Palhares M. O Poder Político e seus Elementos. Recife: Ed. Univ. F. Pe., 1975.

ROJAS, André Serra. Ciência Política. México: Inst. Mexicano de Cultura, 1971.

ROJAS, André Serra. Teoría General del Estado. México: Ed. Manoel Porrua, 1964.

RUSCHEL, Ruy Ruben. Revista da Escola de Direito da Universidade do Vale do Rio dos

Sinos, São Leopoldo, RGS, vol. 5, n. 13, 1975.

RUSSOMANO, Rosah. Dos Poderes Legislativo e Executivo. Rio de Janeiro: Livraria Freitas Bastos S/A, 1976.

SALDANHA, Nelson. Poder constituinte. Tentativa de estudo sociológico e jurídico. São Paulo: Revista dos Tribunais, 1957.

SANCHEZ DE LA TORRE, Angel; LEGAZ Y LACAMBRA, Luis. Curso de Sociologia del Derecho. Madrid: Revista de Derecho Privado, 1965.

SIEYĖS, Emmanuel Joseph. Observaciones sobre el informe del comité de constitución acerca de la nueva organización de Francia. Introdução, estudo premiliminar e compliação: David Pantoja Morán. Fondo de Cultura Económica: México, 1993.

SOUTO, Cláudio. Fundamentos da Sociologia Jurídica. Recife: Ed. UFPE, 1968. 
SOUTO, Cláudio. Introdução ao Direito como Ciência Social. Brasília: Ed. Univ. de Brasília, 1971.

TAVARES, Ana Lúcia De Lyra. A Constituição Brasileira de 1988: subsídios para os comparatistas. Revista de informação legislativa, v. 28, n. 109, p. 71-108, jan./mar. 1991. Disponível em: http://www2.senado.leg.br/bdsf/handle/id/175845. Acesso em: 20 out. 2021.

VERDU, Pablo Lucas. Princípios de Ciência Política. Madrid: Ed. Tecnos, s/d.

VILANOVA, Lourival. Teoria jurídica da Revolução: anotações a margem de Kelsen. In: AS TENDÊNCIAS atuais do D. Público. Rio de Janeiro: Forense, 1976. 